\title{
Design of Miniaturized 10 dB Wideband Branch Line Coupler Using Dual Feed and T-Shape Transmission Lines
}

\author{
Mukesh KUMAR, SK. Nurul ISLAM, Gobinda SEN, Susanta Kumar PARUI, Santanu DAS \\ Dept. of Electronics \& Telecommunication Engineering, Indian Inst. of Engineering Science \& Technology, \\ Shibpur-711103, India
}

\{mukeshnitd415, badshaays, gobinda.dets\}@gmail.com, \{arkapv, santanumdas\}@yahoo.com

Submitted April 3, 2017 / Accepted November 13, 2017

\begin{abstract}
This paper presents a design mechanism of miniaturized wideband branch line coupler (BLC) with loose coupling of $10 \mathrm{~dB}$. Dual transmission lines are used as a feed network which provides a size reduction of $32 \%$ with a fractional bandwidth (FBW) of $60 \%$ for $10 \pm 0.5 \mathrm{~dB}$ coupling but return loss performance is found to be poor in the operating band. For further improvement of return loss performance as well as for size reduction of the BLC, a Tshape transmission lines are used instead of series quarter wavelength transmission lines, and hence the overall size reduction of around $44 \%$ with FBW of $50.4 \%$ is achieved. The return loss and isolation performance is found to be $<15 \mathrm{~dB}$ in the entire operating band $(2.5-4.1 \mathrm{GHz})$ with respect to design frequency $3 G \mathrm{~Hz}$. The proposed $B L C$ is analyzed, fabricated and tested.
\end{abstract}

\section{Keywords}

Branch line coupler, dual line, miniaturization, T-shape transmission line (TL), wideband

\section{Introduction}

Microwave couplers are crucial devices and are used in many microwave subsystems, such as power amplifiers, phase shifter, modulators and power divider and so on [1-4]. In modern microwave circuits there is an increasing demand for wide bandwidth and cost-effective components. Some of the microwave systems require low power to drive sub circuits such as mixers and antenna arrays. Therefore, the ability of couplers to produce arbitrary coupling level is of recent interest.

The branch line coupler (BLC) is the most common among different types of planar couplers, due to its simple design and easy integration with other circuits. The BLC is commonly used for designing tight $(3 \mathrm{~dB})$ coupler. The major drawbacks of designing a BLC are large circuit size and narrow bandwidth. The circuit area becomes large, as it has a $\lambda / 4$ series and shunt transmission lines. Researchers have proposed several techniques to reduce the size and the price of the couplers [5], [6]. Various miniaturization techniques such as defected ground structure [7], varying dielectric constant near the side wall [8], left-handed transmission lines [9], lumped element [10] and dual transmission lines in single layered substrate [11] are presented in literatures. However, the trade off in the size reduction is bandwidth, as the miniaturization occurs bandwidth becomes narrower.

Due to the structural dependence of the BLC on the quarter wavelength $(\lambda / 4)$ and characteristics impedances of transmission line, its application is limited to tight coupling and narrow-band circuits. Design of loose coupled BLC requires high impedance line (narrow line width) which is some extent impractical for design of any microwave circuits. Therefore, the designs of loose BLC's are mere challenges nowadays. Researchers have proposed various design methodology for widening the bandwidth as well as to achieve loose coupling of the BLC's simultaneously, such as series stub [12], symmetrically coupled port feeding network [13], $\lambda / 4$ open circuited coupled lines [14], and $\lambda / 4$ single line transformer as feeding network [15]. In the aforementioned methodologies, extra $\lambda / 4$ transmission lines are inserted as a feed network to achieve wide bandwidth, as a result of which the size of the coupler is increased by half of a wavelength.

In this manuscript, the design and implementation of a miniaturized wideband loose BLC (10dB) is demonstrated. For designing such BLC extra quarter wave length transmission line have been inserted as a feeding network at all the ports of the conventional BLC. To reduce the coupler size, all $\lambda / 4$ sections are replaced by dual transmission lines. Therefore size reduction of $32 \%$ with FBW of $60 \%$ for $10 \pm 0.5 \mathrm{~dB}$ coupling and return loss performance $<10 \mathrm{~dB}$ is achieved. Further miniaturization of the proposed coupler with improved return loss performance is obtained by replacing series $\lambda / 4$ transmission lines by T-shape transmission lines. As a result the overall size reduction of $44 \%$ and return loss performance $<15 \mathrm{~dB}$ in the operating band is obtained without affecting coupler performance. 


\section{Wideband Loose Branch Line Coupler and Its Miniaturization}

\subsection{Design of Wideband 10db BLC}

The major issue related to conventional BLC is narrow bandwidth due to all $\lambda / 4$ transmission lines (series and shunt) which resonates at particular frequency. In order to increase the bandwidth of the BLC the extra $\lambda / 4$ transmission line is used as a feed network. Figure 1 shows the schematic diagram of $10 \mathrm{~dB}$ BLC with quarter wave length extra feed network. All the sections are of quarter wavelength maintained as per the design values of BLC [15]. The values of the characteristic impedances $\left(Z_{1}, Z_{2}\right.$ and $\left.Z_{3}\right)$ are calculated from the reference [15]. The microstrip widths and lengths corresponding to the characteristic impedances for the Arlon substrate with dielectric constant $\varepsilon_{\mathrm{r}}=3.2$, thickness $h=0.787 \mathrm{~mm}$ and loss tangent of 0.002 is shown in Tab. 1. Figure 2 shows the simulated S-parameters response of the BLC. Figure 2 depicts a $46.7 \%$ FBW with coupling level of $10 \pm 0.5 \mathrm{~dB}$ at the operating frequency of $3 \mathrm{GHz}$. The return loss is found to be $18.3 \mathrm{~dB}$ at the lower $(2.3 \mathrm{GHz})$ and $17.2 \mathrm{~dB}$ at the upper $(3.8 \mathrm{GHz})$ edges of the frequency band; similarly at those frequencies the isolation is $17.8 \mathrm{~dB}$ and $15 \mathrm{~dB}$, respectively.

\subsection{Miniaturization of Wideband 10dB BLC using Dual Transmission Line}

As mentioned in the particular section the bandwidth of BLC is increased by introducing extra $\lambda / 4 \mathrm{TL}$ as feeding network resulting in the size increment of BLC. By introducing extra element at all ports, the size of the coupler is increased by half of the wave length. In order to reduce the overall size, dual TL is used in place of single $\lambda / 4$-long TL at each port. In a dual TL, $\lambda / 4$ TL of initial design is split into a parallel TL's structure as shown in Fig. 3.

\begin{tabular}{|c|c|c|c|c|}
\hline $\begin{array}{c}\text { Impedance } \\
(\mathbf{\Omega})\end{array}$ & $\begin{array}{c}\mathrm{Z}_{0} \\
(50)\end{array}$ & $\begin{array}{c}\mathrm{Z}_{1} \\
(36)\end{array}$ & $\begin{array}{c}\mathrm{Z}_{2} \\
(24.6)\end{array}$ & $\begin{array}{c}\mathrm{Z}_{3} \\
(77.76)\end{array}$ \\
\hline $\begin{array}{c}\text { Width (mm), } \\
\text { Length (mm) }\end{array}$ & $\begin{array}{c}1.89, \\
5\end{array}$ & 3.07, & 5, & 0.8, \\
\hline
\end{tabular}

Tab. 1. Dimensions of $10 \mathrm{~dB}$ reference BLC.

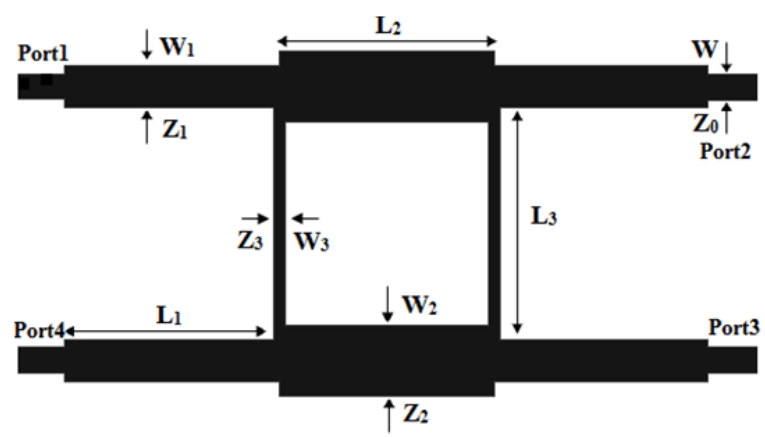

Fig. 1. BLC with $\lambda / 4$ feeding network.

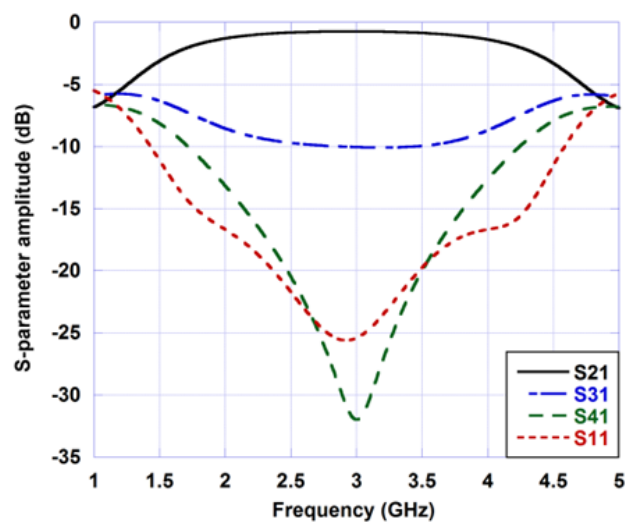

(a)

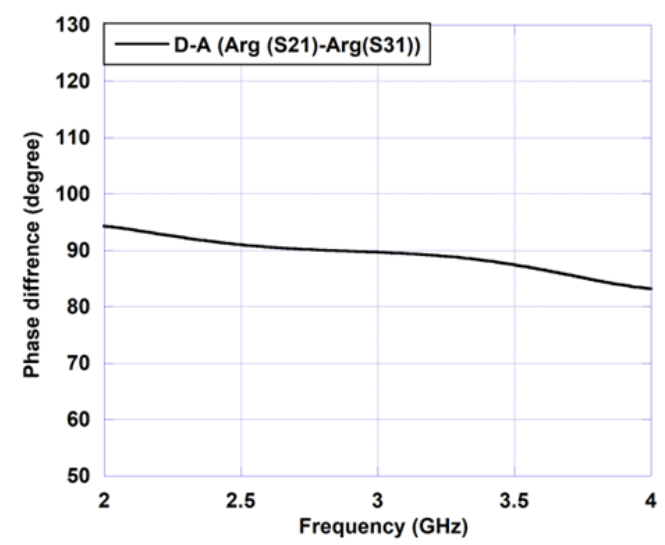

(b)

Fig. 2. (a) S-parameters response of BLC. (b) Phase difference $(<$ S21 - $<$ S31).

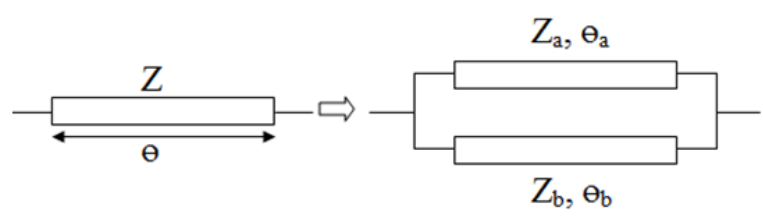

Fig. 3. Equivalent circuit of single TL with dual TL.

Here, $Z_{\mathrm{a}}, Z_{\mathrm{b}}, \theta_{\mathrm{a}}$, and $\theta_{\mathrm{b}}$ are defined as the characteristic impedances and the electrical lengths of dual TL's, respectively, and $\theta_{\mathrm{a}}<\theta=90^{\circ}<\theta_{\mathrm{b}}$. Here $\theta\left(90^{\circ}\right)$ is the electrical length of the single TL and the transmission matrix (ABCD parameter) is written in (1). Similarly ABCD matrixes are written for both lines 1 and 2 in (2), (3). The expression for the characteristic impedances and the electrical lengths are obtained from relating (1-3) and giving in (4-6). The characteristic impedances $\left(Z_{\mathrm{a}}\right.$ and $\left.Z_{\mathrm{b}}\right)$ of these dual-lines are calculated from (4-6) by properly selecting the value of their electrical lengths $\left(\theta_{\mathrm{a}}\right.$ and $\left.\theta_{\mathrm{b}}\right)$. In order to reduce the circuit size, the condition $\theta_{\mathrm{a}}<\theta=90^{\circ}<\theta_{\mathrm{b}}$ and $\theta_{\mathrm{a}}+\theta_{\mathrm{b}}=$ $180^{\circ}$ must be satisfied. Therefore this dual transmission lines are composed of two high impedance lines with high impedance and different electrical lengths. Out of these two lines, longer one $\left(\theta_{\mathrm{b}}\right)$ is meander in shape to reduce the circuit area.

The layout of the proposed BLC and simulated Sparameters response are shown in Fig. 4 and 5 respectively. 


$$
\begin{gathered}
{\left[\begin{array}{cc}
A & B \\
C & D
\end{array}\right]_{\theta}=\left[\begin{array}{cc}
0 & \mathrm{j} Z \\
\mathrm{j} Y & 0
\end{array}\right],} \\
{\left[\begin{array}{cc}
A_{\mathrm{a}} & B_{\mathrm{a}} \\
C_{\mathrm{a}} & D_{\mathrm{a}}
\end{array}\right]_{\text {line } 1}=\left[\begin{array}{cc}
\cos \theta_{\mathrm{a}} & \mathrm{j} Z_{0} \sin \theta_{\mathrm{a}} \\
\mathrm{j} Y_{\mathrm{a}} \sin \theta_{\mathrm{a}} & \cos \theta_{\mathrm{a}}
\end{array}\right],} \\
{\left[\begin{array}{cc}
A_{\mathrm{b}} & B_{\mathrm{b}} \\
C_{\mathrm{b}} & D_{\mathrm{b}}
\end{array}\right]_{\text {line } 2}=\left[\begin{array}{cc}
\cos \theta_{\mathrm{b}} & \mathrm{j} Z_{0} \sin \theta_{\mathrm{b}} \\
\mathrm{j} Y_{\mathrm{a}} \sin \theta_{\mathrm{b}} & \cos \theta_{\mathrm{b}}
\end{array}\right],} \\
Z_{\mathrm{a}}=Z \frac{\cos \theta_{\mathrm{b}}-\cos \theta_{\mathrm{a}}}{\sin \theta_{\mathrm{a}} \cos \theta_{\mathrm{b}}}, \\
Z_{\mathrm{b}}=-Z \frac{\cos \theta_{\mathrm{b}}-\cos \theta_{\mathrm{a}}}{\sin \theta_{\mathrm{a}} \cos \theta_{\mathrm{b}}} \\
\frac{Z_{\mathrm{a}}}{Z_{\mathrm{b}}}=-\frac{\tan \theta_{\mathrm{b}}}{\tan \theta_{\mathrm{a}}} .
\end{gathered}
$$

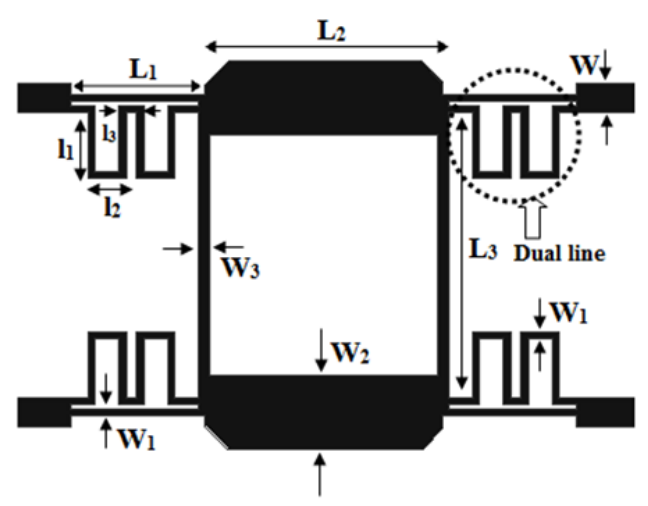

Fig. 4. Layout of BLC with dual TL as a feeding network.

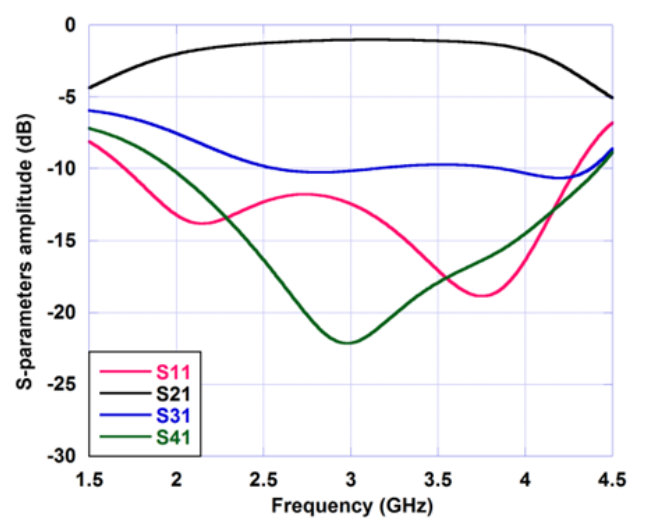

Fig. 5. Simulated S-parameters of $10 \mathrm{~dB}$ BLC with dual TL.

From Fig. 5 it is clear that by incorporating the dual transmission line in place of $\lambda / 4$ TLs as a feed network the return loss $\left(S_{11}\right)$ performance drastically changes in the operating frequency band. The return loss performance is degraded due to the step changes (cause parasitic effects) at the line joint between the dual TL, series and shunt quarter wavelength line. The S11 performances are found to be $12.2 \mathrm{~dB}$ at the lower edge $(2.5 \mathrm{GHz})$ and $10.3 \mathrm{~dB}$ at upper edge $(4.3 \mathrm{GHz})$ of the frequency band with isolation of

$14.9 \mathrm{~dB}$ and $12.54 \mathrm{~dB}$, respectively. To improve the performance and for further reduction of the coupler size, a $\mathrm{T}$ shape TL is used in place of series quarter wavelength line.

\subsection{Miniaturization and Performance Improvement of Wideband 10dB BLC using T-shape Transmission Line}

To improve the performance as well as the size reduction of the BLC, series quarter wavelength TL is replaced by two series lines and one open stub in the middle which looks like a letter ' $T$ ' as shown in Fig. 6. The ABCD matrix of a series $\lambda / 4 \mathrm{TL}$ is given by (1) and open stub is given in (7) where admittance of the stub $Y=\mathrm{j} \tan \theta_{\mathrm{d}} / Z_{\mathrm{d}}$. Furthermore, the ABCD matrix for each of the two TL that has a characteristic impedance of $Z_{\mathrm{c}}$ and electrical length of $\theta_{c}$ is given by (8). The overall transmission matrix of a ' $\mathrm{T}$ ' shape TL is equated with $\lambda / 4$ TL matrix in order to obtain the characteristic impedances and electrical lengths of the proposed T-shape model as shown in (9).

$$
\begin{aligned}
& {\left[\begin{array}{ll}
A & B \\
C & D
\end{array}\right]_{\mathrm{S}}=\left[\begin{array}{ll}
1 & 0 \\
Y & 1
\end{array}\right]} \\
& {\left[\begin{array}{ll}
A & B \\
C & D
\end{array}\right]_{\mathrm{L}}=\left[\begin{array}{cc}
\cos \theta_{\mathrm{c}} & \mathrm{j} Z_{\mathrm{c}} \sin \theta_{\mathrm{c}} \\
\mathrm{j} Y_{\mathrm{c}} \sin \theta_{\mathrm{c}} & \cos \theta_{\mathrm{c}}
\end{array}\right] \text {, }} \\
& {\left[\begin{array}{cc}
A & B \\
C & D
\end{array}\right]_{\theta}=\left[\begin{array}{cc}
0 & \mathrm{j} Z \\
\mathrm{j} Y & 0
\end{array}\right]=\left[\begin{array}{cc}
A & B \\
C & D
\end{array}\right]_{\mathrm{L}} \times\left[\begin{array}{cc}
A & B \\
C & D
\end{array}\right]_{\mathrm{S}} \times\left[\begin{array}{cc}
A & B \\
C & D
\end{array}\right]_{\mathrm{L}},} \\
& A=D=0=\cos ^{2} \theta_{\mathrm{c}}-\sin ^{2} \theta_{\mathrm{c}}-\frac{Z_{\mathrm{c}} \sin \theta_{\mathrm{c}} \cos \theta_{\mathrm{c}} \tan \theta_{\mathrm{d}}}{Z_{\mathrm{d}}}, \\
& B=\mathrm{j} Z=\mathrm{j} Z_{\mathrm{c}} \sin 2 \theta_{\mathrm{c}}-\frac{\mathrm{j} Z_{\mathrm{c}}^{2} \sin ^{2} \theta_{\mathrm{c}} \tan \theta_{\mathrm{d}}}{Z_{\mathrm{d}}}, \\
& C=\mathrm{j} Y=\frac{\mathrm{j} \sin 2 \theta_{\mathrm{c}}}{Z_{\mathrm{c}}}+\frac{\mathrm{j} \cos ^{2} \theta_{\mathrm{c}} \tan \theta_{\mathrm{d}}}{Z_{\mathrm{d}}}, \\
& Z_{\mathrm{c}}=\frac{Z}{\tan \theta_{\mathrm{c}}} \\
& Z_{\mathrm{d}}=\frac{Z_{\mathrm{c}} \tan \theta_{\mathrm{d}} \tan 2 \theta_{\mathrm{c}}}{2} .
\end{aligned}
$$

The ABCD parameters are written in $(10-12)$. Solving (10-11), the characteristic impedances $Z_{\mathrm{c}}$ and $Z_{\mathrm{d}}$ of stub loaded T-shape TL in terms of electrical length are obtained as described in (13-14). The values of $b$ and $c$ in Fig. 7 are evaluated by properly choosing the electrical lengths $\left(\theta_{\mathrm{c}}\right.$ and $\left.\theta_{\mathrm{d}}\right)$ of series line and open stub in order to achieve miniaturization. For this $\theta_{\mathrm{c}}=20^{\circ}$ and $\theta_{\mathrm{d}}=40^{\circ}$ are chosen. Therefore value of $b$ is obtained from $\theta_{\mathrm{d}}=40^{\circ}$ and the value of $c$ is obtained from $Z_{\mathrm{d}}$ by using (14). The layout of the proposed BLC is shown in Fig. 7. The simulated Sparameters responses of the proposed coupler are shown in Fig. 8. 


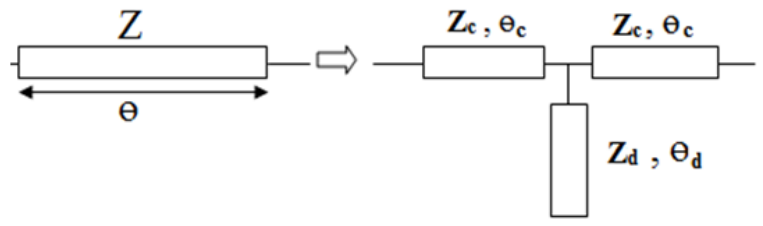

Fig. 6. Equivalent model of single TL as T-shape TL.

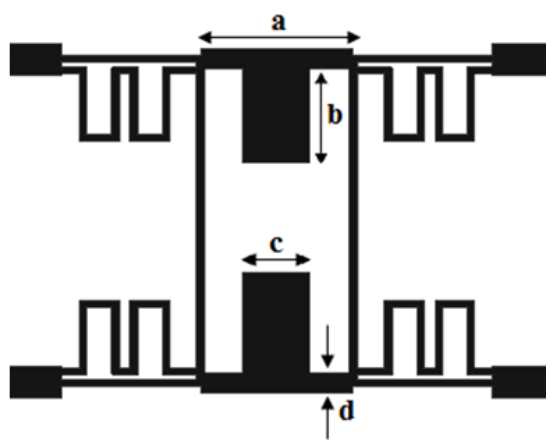

Fig. 7. Layout of the proposed BLC.

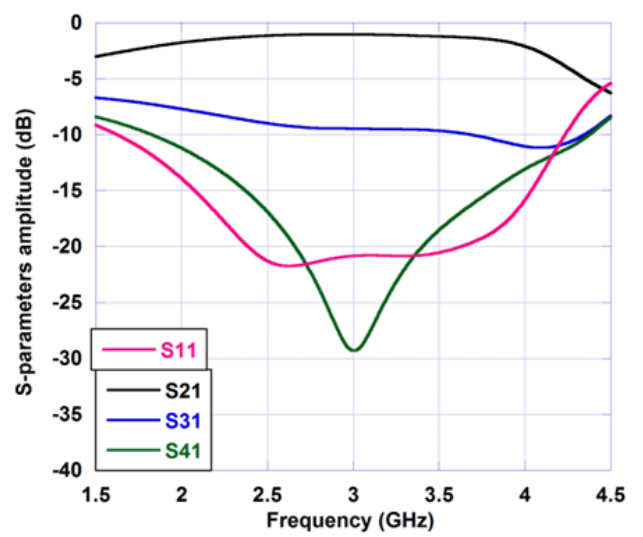

Fig. 8. Simulated S-parameters response of proposed coupler.

From Fig. 8 it is evident the return loss (S11) performance is improved due to incorporating the T-shape transmission line in place of series $\lambda / 4$-long TL. The return loss (S11) performance is improved by minimum $-8 \mathrm{~dB}$ in the whole frequency band. The isolation (S41) performance is improved by $-7 \mathrm{~dB}$ at the operating frequency.

\section{Experimental Results}

The proposed 10-dB BLC's are designed and fabricated at operating frequency of $3 \mathrm{GHz}$ : Design A consists of a dual TL as a feed network and Design B consists of a dual TL along with T-shape TL for miniaturization of wideband BLCs. In design A, electrical lengths of feed network, $\theta_{1}$ and $\theta_{2}$ are chosen as $45^{\circ}\left(L_{1}=L_{\mathrm{a}}\right)$ and $135^{\circ}$ $\left(L_{\mathrm{b}}=4 l_{1}+2 l_{2}+3 l_{3}\right)$ respectively and the corresponding characteristic impedances $\left(Z_{\mathrm{a}}\right.$ and $\left.Z_{\mathrm{b}}\right)$ are calculated from (4-6), where $Z$ is $36 \Omega$, therefore $Z_{\mathrm{a}}=Z_{\mathrm{b}}=102 \Omega$. Therefore size reduction of $32 \%$ is achieved in design $A$. In design $B$, the characteristic impedances $\left(Z_{\mathrm{c}}\right.$ and $\left.Z_{\mathrm{d}}\right)$ and electrical lengths $\left(\theta_{\mathrm{c}}\right.$ and $\left.\theta_{\mathrm{d}}\right)$ are evaluated from (13-14) where $Z$ is taken as $24.6 \Omega$ and the electrical lengths $\left(\theta_{\mathrm{c}}\right.$, and $\left.\theta_{\mathrm{d}}\right)$ are selected as $20^{\circ}$ and $40^{\circ}$, respectively. Therefore the overall size reduction of around $44 \%$ is achieved in design $B$. The other parameters remain unchanged.

The proposed couplers have been fabricated on Arlon substrate of dielectric constant $\varepsilon_{\mathrm{r}}=3.2$, thickness $h=$ $0.787 \mathrm{~mm}$ and loss tangent of 0.002 . The characteristic impedances and optimized design parameters of BLC's for design A and B are tabulated in Tab. 2. The photographs of the fabricated prototype for both design A and B are shown in Fig. 9.

An Agilent vector network analyzer is used to test the performance of the fabricated BLC's and compared with the simulated results to ensure that the coupler design exhibits good performance in the real time environment. Figure 10 and 11 show the simulated (Sim) and measured (Mea) S-parameter responses for both designs A and B, respectively. Table 3 illustrates the simulated and measured S-parameters details, FBW and size of proposed couplers (design A and B). FBW is found to be $60 \%$ for the coupling level of $10 \pm 0.5 \mathrm{~dB}$, phase imbalance $90^{\circ} \pm 10^{\circ}$ and return loss and isolation are $<-10 \mathrm{~dB}$ and $<-15 \mathrm{~dB}$ for design A, respectively. Similarly for design $\mathrm{B}, \mathrm{FBW}$ is $50.04 \%$ for the coupling (C) level of $10 \pm 0.5 \mathrm{~dB}$, phase imbalance $90^{\circ} \pm 10^{\circ}$ with return loss and isolation performance better than around $-15 \mathrm{~dB}$.

\begin{tabular}{|c|c|c|c|}
\hline \multirow{2}{*}{$\begin{array}{c}\text { Design A } \\
\text { Impedance ( }(\Omega)\end{array}$} & $Z_{1}=36$ & \multirow{2}{*}{$Z_{2}=24.6$} & \multirow{2}{*}{$Z_{3}=77.76$} \\
\hline & $Z_{a}=Z_{b}=102$ & & \\
\hline $\begin{array}{l}\text { Width(mm), } \\
\text { length(mm) }\end{array}$ & $\begin{array}{c}\mathrm{W}_{1}=0.4 \\
\mathrm{~L}_{1}=\mathrm{L}_{\mathrm{a}}=8, \mathrm{~L}_{\mathrm{b}}=24\end{array}$ & $\begin{array}{l}\mathrm{W}_{2}=4.5 \\
\mathrm{~L}_{2}=14.6\end{array}$ & $\begin{array}{l}\mathrm{W}_{3}=0.5 \\
\mathrm{~L}_{3}=16.3\end{array}$ \\
\hline \multirow{2}{*}{$\begin{array}{c}\text { Design B } \\
\text { Impedance }(\Omega)\end{array}$} & $Z_{1}=36$ & $Z_{2}=24.6$ & \multirow[b]{2}{*}{$Z_{3}=77.76$} \\
\hline & $Z_{\mathrm{a}}=\mathrm{Z}_{\mathrm{b}}=102$ & $\begin{array}{l}Z_{c}=67.57, \\
Z_{d}=23.79\end{array}$ & \\
\hline $\begin{array}{l}\text { Width(mm), } \\
\text { length(mm) }\end{array}$ & $\begin{array}{c}\mathrm{W}_{1}=0.4 \\
\mathrm{~L}_{1}=\mathrm{L}_{\mathrm{a}}=8, \mathrm{~L}_{\mathrm{b}}=24\end{array}$ & $\begin{array}{l}a=9, b=5.6, \\
c=4, d=1.2\end{array}$ & $\begin{array}{l}\mathrm{W}_{3}=0.5 \\
\mathrm{~L}_{3}=16.3\end{array}$ \\
\hline
\end{tabular}

Tab. 2. Dimensions of the proposed BLC's.

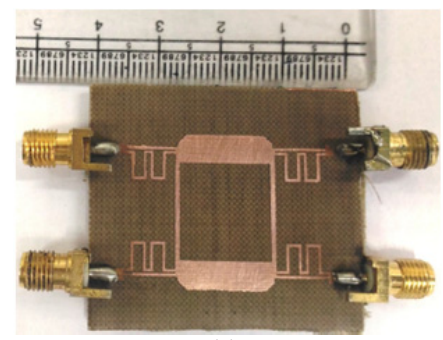

(a)

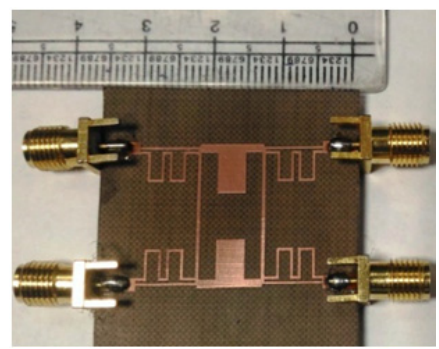

(b)

Fig. 9. Photograph of fabricated prototype of the proposed BLC's: (a) design A, (b) design B. 


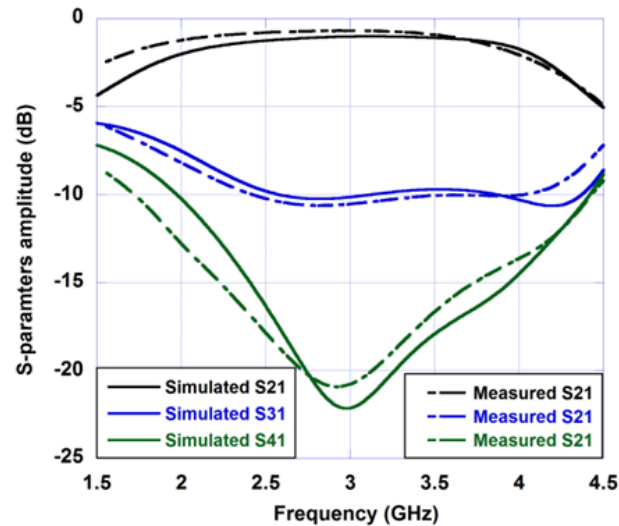

(a)

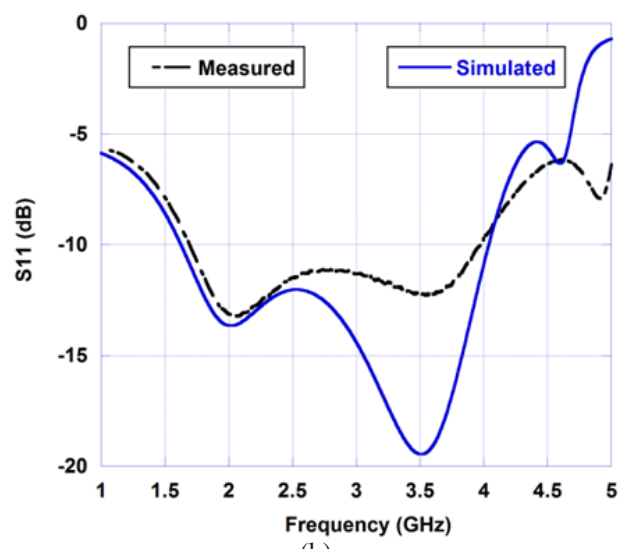

(b)

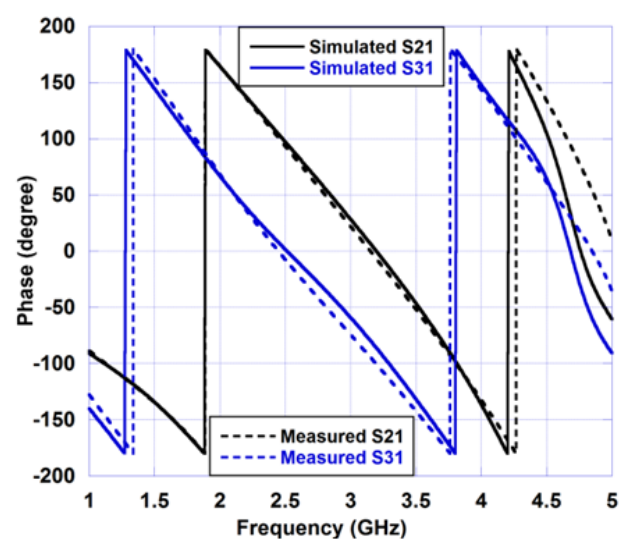

(c)

Fig. 10. Simulated and measured S-parameters response of design A: (a) S21, S31, S41, (b) S11, (c) S21 and S31 phase.

\begin{tabular}{|c|c|c|c|}
\hline Parameters & $\begin{array}{c}\lambda / 4-\text {-long FN } \\
\text { Sim }\end{array}$ & $\begin{array}{c}\text { Design A } \\
\text { Sim/Mea }\end{array}$ & $\begin{array}{c}\text { Design B } \\
\text { Sim/Mea }\end{array}$ \\
\hline S21 & $2.4-4.21$ & $2.3-4.1 / 2.1-4.1$ & $2.41-4.1 / 2.5-4.1$ \\
\hline S31 & $2.35-3.75$ & $2.4-4.35 / 2.2-4$ & $2.4-4 / 2.4-3.9$ \\
\hline S41 & $2.14-3.81$ & $2.4-4.0 / 2.2-3.7$ & $2.4-3.8 / 2.4-3.7$ \\
\hline S11 & $1.8-4.31$ & $1.63-4.03 / 1.7-4$ & $2.1-4.02 / 2-4$ \\
\hline FBW & $46.7 \%$ & $65 \% / 60 \%$ & $53 \% / 50.4 \%$ \\
\hline Area $\left(\mathrm{mm}^{2}\right)$ & $45.9 \times 16.1$ & $31 \times 16.2$ & $25.5 \times 16.2$ \\
\hline
\end{tabular}

Tab. 3. Simulated and measured S-parameter performance of the proposed BLCs.

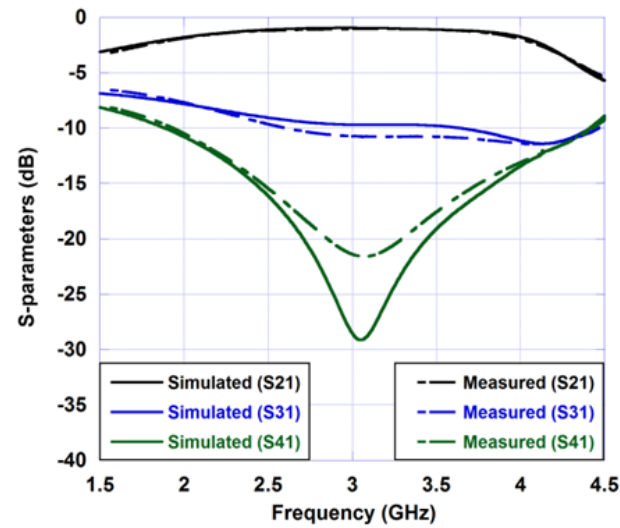

(a)

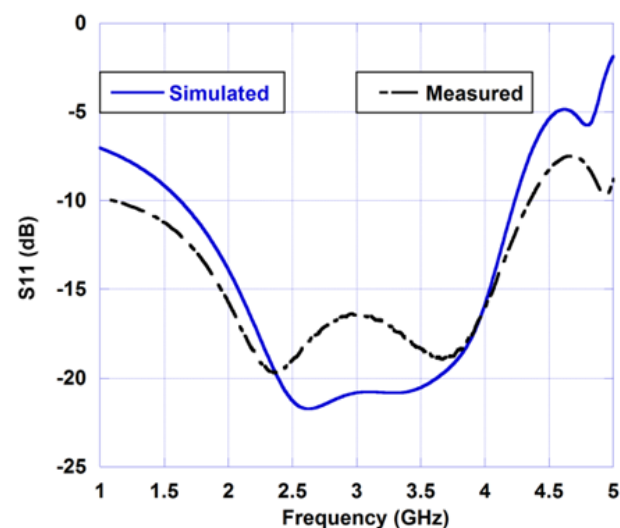

(b)

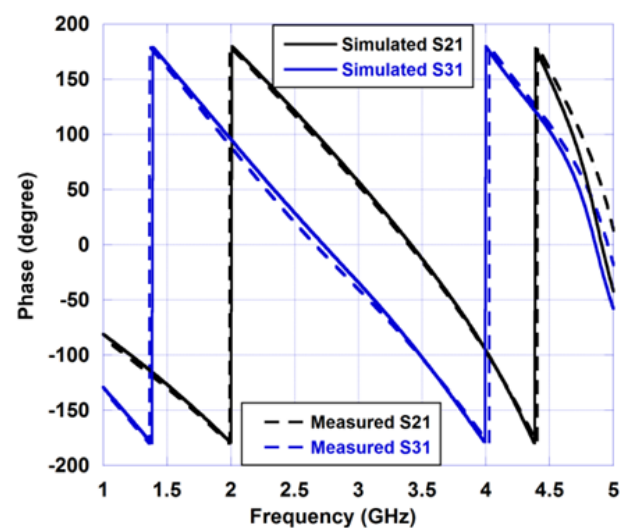

(c)

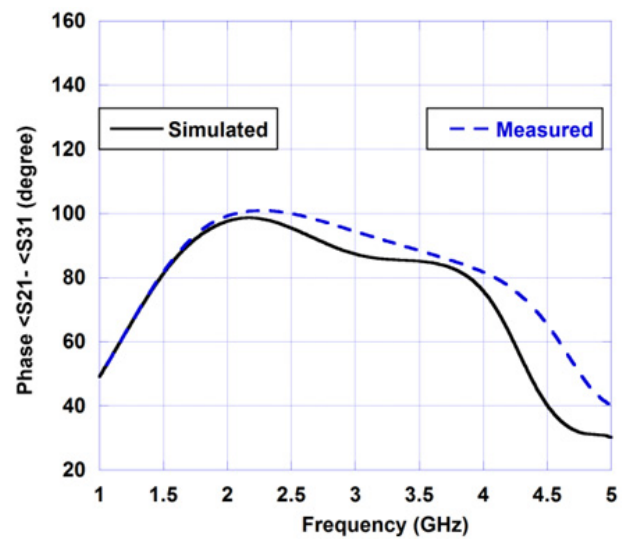

(d)

Fig. 11. Simulated and measured S-parameters response of design B: (a) S21, S31, S41, (b) S11, (c) S21 and S31 phase, (d) phase difference $(<\mathrm{S} 21-<\mathrm{S} 31)$. 


\begin{tabular}{|c|c|c|c|c|c|c|c|}
\hline Ref. & $\mathbf{f}_{\mathbf{0}}(\mathbf{G H z})$ & $\left.\left|\mathbf{S}_{\mathbf{1 1}}\right| \mathbf{( d B}\right)$ & $|\mathbf{S} \mathbf{2 1}| \mathbf{( d B})$ & $\mathbf{C} \pm \mathbf{r}(\mathbf{d B})$ & $\left.\left|\mathbf{S}_{\mathbf{4 1}}\right| \mathbf{( d B}\right)$ & $\mathbf{F B W}(\mathbf{\%})$ & $\mathbf{A r e a}\left(\mathbf{m m} \mathbf{2}^{\mathbf{2}}\right)$ \\
\hline$[\mathbf{1 2}]$ & 2.9 & 20 & 4 & $3 \pm 0.5$ & 20 & 30 & $0.75 \lambda_{\mathrm{g}} \times 0.25 \lambda_{\mathrm{g}}$ \\
\hline$[\mathbf{1 3}]$ & 1 & 10 & 3.1 & $3.4 \pm 0.6$ & 10 & 52 & $0.75 \lambda_{\mathrm{g}} \times 0.25 \lambda_{\mathrm{g}}$ \\
\hline$[\mathbf{1 4}]$ & 5.9 & 20 & 3.6 & $3.6 \pm 0.5$ & 20 & 49 & $0.85 \lambda_{\mathrm{g}} \times 0.24 \lambda_{\mathrm{g}}$ \\
\hline$[\mathbf{1 5}]$ & 3 & 15 & 1 & $10.1 \pm 0.3$ & 19.8 & 50.9 & $0.72 \lambda_{\mathrm{g}} \times 0.26 \lambda_{\mathrm{g}}$ \\
\hline Design A & 3 & 14 & 1.02 & $10.1 \pm 0.5$ & 22 & 60.4 & $0.50 \lambda_{\mathrm{g}} \times 0.25 \lambda_{\mathrm{g}}$ \\
\hline Design B & 3 & 21 & 0.95 & $10.5 \pm 0.5$ & 29 & 55.4 & $0.40 \lambda_{\mathrm{g}} \times 0.25 \lambda_{\mathrm{g}}$ \\
\hline
\end{tabular}

Tab. 4. Comparisons of wideband BLC with the proposed one.

The proposed design is aimed at minimization of the reference (existing) BLC [15] with proposed technique by giving substantially miniaturization of $44 \%$. It is to be further noted that despite the miniaturization, no other performance factors are degraded. Herein lies the advantage of the proposed design over the existing design since the proposed structure is very compact thus making it suitable to be used in compact and sophisticated microwave systems. The wide band property along with other characteristics of the proposed design is also compared with some other works and the comparison is tabulated in Tab. 4. It is found that the BLC in Ref. [14] is larger in size in comparison with that in Ref. [12], [13]. The proposed coupler is smaller in size, which is $52 \%$ and $47 \%$ smaller compared to the BLC in Ref. [14] and Ref. [12], [13], respectively. Also the FBW of the proposed design is more compared with the Ref. [12-14].

\section{Conclusion}

A miniaturized wideband BLC is designed using Tshape TL section and dual TL as a feed network in place of $\lambda / 4$-long series TL. The proposed design provides an overall size reduction of $44 \%$ compared to the BLC with single quarter wavelength section as feed network at all the ports. The measured results are completely compiled with the simulated frequency response for $50.4 \% \mathrm{FBW}$ with isolation and return loss better than $15 \mathrm{~dB}$. The proposed structure is fabricated with standard printed circuit board which is cost effective in terms of mass production, as a result of which it has great demand in microwave circuits.

\section{Acknowledgments}

This work is supported by the Ministry of Electronics and Information Technology (MeitY) for providing financial support under Visvesvaraya $\mathrm{PhD}$ scheme.

\section{References}

[1] LI, Y., SUN, S., YANG, F. Dual-band hybrid patch coupler with embedded spiral open stubs. In Proceedings of Asia Pacific Microwave Conference. Kaohsiung (Taiwan), 2012, p. 169-171. DOI: 10.1109/APMC.2012.6421535
[2] SUN, S., ZHU, L. Miniaturized patch hybrid couplers using asymmetrically loaded cross slots. IET Microwaves, Antennas and Propagation, 2010, vol. 4, no. 9, p. 1427-1433. DOI: 10.1049/IET-MAP.2009.0293

[3] TSAI, K. Y., YANG, H. S., CHEN, J. H., CHEN, Y. J. E. A miniaturized $3 \mathrm{~dB}$ branch-line hybrid coupler with harmonics suppression. IEEE Microwave and Wireless Components Letters, 2011, vol. 21, no. 10, p. 537-539. DOI: 10.1109/LMWC.2011.2164901

[4] GHALI, H., MOSELHY. T. A. Miniaturized fractal rat-race, branch-line, and coupled-line hybrids. IEEE Transactions on Microwave Theory and Techniques, 2004, vol. 52, no. 11, p. 2513 to 2520 . DOI: 10.1109 /TMTT.2004.837154

[5] TANAKA, H., BANBA, N., ARI, S., NISHIKAWA, T. 2 GHz one octave-band 90 degree hybrid coupler using coupled meander line optimized by 3-D FEM. In IEEE MTT-S International Microwave Symposium Digest. San Diego (CA, USA), 1994, vol. 2, p. 903 to 906. DOI: 10.1109/MWSYM.1994.335211

[6] VOGEL, R. W. Analysis and design of lumped- and lumpeddistributed-element directional couplers for MIC and MMIC applications. IEEE Transactions on Microwave Theory and Techniques, 1992, vol. 40, no. 2, p. 253-262. DOI: $10.1109 / 22.120097$

[7] MOHRA, A. S., ALKANHAL, M. A., ABDULlAH, E. A. Sizereduced defected ground microstrip directional coupler. Microwave and Optical Technology Letters, 2010, vol. 52, p. 1933-1937. DOI: 10.1002/mop.25410

[8] YAMAMOTO, S., HIROKAWA, J., ANDO, M. Length reduction of a short-slot directional coupler in a single-layer dielectric substrate waveguide by removing dielectric near the side walls of the coupler. In IEEE Antennas and Propagation Society Symposium. Monterey (CA, USA), 2004, vol. 3 p. 2353-2356. DOI: $10.1109 /$ APS.2004.1331844

[9] XINHUA REN, QI ZHU, SHANJIA XU. Design of directional coupler with left-handed transmission line. In IEEE Antennas and Propagation Society International Symposium, 2006, p. 4157 to 4160.

[10] ABDAlla, M. A. Y., PHANG, K., ElEFTHERIADES, G. V. A compact highly reconfigurable CMOS MMIC directional coupler. IEEE Transactions on Microwave Theory and Techniques, 2008, vol. 56, no. 2, p. 305-319. DOI: 10.1109/TMTT.2007.913360

[11] TANG, C. W., CHEN, M. G., TSAI, C. H. Miniaturization of microstrip branch-line coupler with dual transmission lines. IEEE Microwave and Wireless Components Letters, 2008, vol. 18, no. 3, p. 185-187. DOI: 10.1109/LMWC.2008.916798

[12] KAWAI, T., TANIGUCHI, H., OHTA, I., ENOKIHARA, A. Broadband branch-line coupler with arbitrary power split ratio utilizing microstrip series stubs. In40th European Microwave Conference. Paris (France), 2010, p. 1170-1173. DOI: 10.23919/EUMC.2010.5616093

[13] WONG, Y. S., ZHENG, S. Y., CHAN, W. S. Multifold bandwidth branch line coupler with filtering characteristic using coupled port 
feeding. Progress In Electromagnetic Research, 2011, vol. 118, p. 17-35. DOI: 10.2528/PIER11041401

[14] ARRIOLA, W. A., LEE, J. Y., KIM, D. I. S. Wideband 3 dB branch line coupler based on $\lambda / 4$ - open circuited coupled lines. IEEE Microwave and Wireless Components Letters, 2011, vol. 21, no. 9, p. 486-488. DOI: 10.1109/LMWC.2011.2138687

[15] LEE, L., LEE, Y. Wideband branch-line couplers with singlesection quarter-wave transformers for arbitrary coupling levels. IEEE Microwave and Wireless Components Letters, 2012, vol. 22, no. 1, p. 19-21. DOI: 10.1109/LMWC.2011.2176723

\section{About the Authors...}

Mukesh KUMAR (1989) received the B.Tech. degree in Electronic and Tele-comm. Engineering from the Biju Patnaik University of Technology, Rourkela, Orissa in 2011, and the M.Tech degree in Electronics and Communication Engineering from the National Institute of Technology, Durgapur in 2015. He is currently pursuing the Ph.D. degree in Microwave Engineering with the Electronics and Telecommunication Engineering Dept., Indian Inst. of Engineering Science and Technology, Shibpur, Howrah, India. His current research interests include microwave planar circuits, power divider, couplers.

SK. Nurul ISLAM (1989) received the B.Tech. degree in 2011 and the M.Tech degree in 2013, both in Electronic and Comm. Engineering from the West Bengal University of Technology, Kolkata. He is currently pursuing the Ph.D. degree in Microwave Engineering with the Electronics and Telecommunication Engineering Dept., Indian Inst. of Engineering Science and Technology, Shibpur, Howrah, India. His current research interests include microwave planar antenna, metamaterial.

Gobinda SEN (1988) received the B.Tech. degree in Electronic and Comm. Engineering from the West Bengal Uni- versity of Technology in 2010, and the M.Tech degree in Communication Engineering from the University of Kalyani, Kalyani in 2013. He is currently pursuing the Ph.D. degree in Microwave Engineering with the Electronics and Telecommunication Engineering Dept., Indian Inst. of Engineering Science and Technology, Shibpur, Howrah, India. His current research interests include metamaterial inspired structure for performance improvement of antenna, absorbers.

Susanta Kumar PARUI (1965) received the B.Sc degree in Physics, and the B.Tech. degree in Radio Physics and Electronics from the University of Calcutta in 1987 and 1990, respectively. He has done the Master degree in Microwave Communication Engineering from the Bengal Engineering College, India in 1993. From 1993 to 2000, he worked as an Instrument Engineer. Since 2000, he is associated with the Dept. of Electronics and Telecommunication Engineering, Bengal Engineering and Science University, India and presently holds the post of Senior Lecturer. His current research interests include the planar circuits, filters, antenna elements and electromagnetic bandgap structures.

Santanu DAS (1968) received the B.E. degree in Electronic and Telecom. Engineering from the Bengal Engineering College in 1989, and the M.E degree in Microwave Engineering from the Jadavpur University, Calcutta in 1992. He obtained the Ph.D (Engineering) degree in the year 1998 from the Jadavpur University. As Lecturer in Electronics and Telecommunication Engineering, he joined the department of the Bengal Engineering and Science University in 1998 and presently holds the post Professor at the same department. His current research interests include the microstrip circuits, antenna elements and arrays, FSS and defected ground structures. He is a life member of the Institution of Engineers, India. 